\title{
The Causes and Enlightenment of Post-Modern Film Culture in the 5G Era
}

\author{
Heqiang Zhou' ${ }^{*}$, Lei Que ${ }^{2}$ \\ ${ }^{1}$ Department of Communication and Media, Guangzhou Huashang College, Guangzhou 511300, China \\ 2Department School of Fine Arts and Design, Guangzhou University, Guangzhou 510000, China \\ *Corresponding author: Heqiang Zhou, weich151353@163.com
}

\begin{abstract}
With the increasing influence of 5G technology on film art, the postmodern culture contained therein is also gradually becoming obvious. Understanding the context of the $5 \mathrm{G}$ era and clarifying the origin of postmodern film culture can help us analyze the cause of the rise of postmodern film culture, especially the important influence of the expansion of film application scenes, the innovation of the whole industry chain and the evolution of film aesthetics on the rise of postmodern film culture. In addition, we should also consider the film culture under the postmodernism of 5G era, and explore the way to stick to the benign development of film creation and film industry in order to enhance our cognition and appreciation of postmodern film culture, to maximize the positive factors of postmodern film culture, and to promote the healthy and prosperous development of Chinese film production, creation and industry.
\end{abstract}

Keywords: Scene; Aesthetics; Industry chain; 5G Era; Postmodern culture

Publication date: September 2021; Online publication: September 30, 2021

\section{Introduction}

Since the emergence of film art, people's vision and imagination for the future are usually presented through the films. Whether in the movie "The Matrix" or "Ready Player One," the characters live in a virtual world. With the development of 5G technology, similar scenes in many sci-fi movies will become a reality or are in the process of becoming a reality. In the $5 \mathrm{G}$ era, everything is connected. Virtual reality (VR) devices will have free access to the interior and exterior spaces. At the same time, in the "post-epidemic" era of intervention and coercion, the postmodern cultural context in the 5G information age will also be presented to us in a more innovative way. "Social and cultural values have changed, and the crisis makes us think about life, the country and society in a new way ${ }^{[1]}$."

\section{Context of 5G era and postmodern film culture}

\subsection{Era of $5 \mathrm{G}$ communication technology}

$5 \mathrm{G}$ is the abbreviation of " $5^{\text {th }}$ Generation," which refers to the $5^{\text {th }}$ Generation mobile network communication technology. With the continuous development of mobile communication technology, 5G networks can meet the needs of different members of the wireless network system, provide customers with network services of higher level, solve the problems of information communication between people, people and things, and things, and improve the efficiency of data transmission. Compared with 4G networks, 5G has the advantages of high reliability, low delay and low power consumption. It is a comprehensive solution integrating traditional wireless access technology and new wireless technology. Large capacity of 5G network can effectively promote the development of wide area of things, life cycle in the extension of the Internet of things node at the same time, can reduce the communication cost and application scope of the 
Internet of things, improve the intelligent level of communication, strengthen the communication industry and the relationship between the film and other industries, promote the reform and upgrade of the film industry intelligent, and promote the layout optimization, promotion and path innovation of the film industry, thus bringing new meaning to the postmodern culture of the film.

\subsection{Postmodern culture of movies}

Postmodern culture, also known as postmodern culture or postmodernism, "is a trend of thought in art, philosophy and other cultural fields that took place in the 1960s and became popular in the west in the 1970 s and 1980s ${ }^{[2]}$. Although there is no consensus on the causes and conditions of postmodern culture in the academic circle, the research on postmodern culture, postmodern films and their theories has been accumulated up to now. There is no doubt that postmodern culture and the transformation of modern and contemporary information and communication technology, especially the development of the Internet, artificial intelligence (AI) and other technologies are inseparable, and these technologies were assimilated into the film art and film industry, thereby into the mass culture and consumer culture.

With the advent of 5G, scenes that were previously only seen in movies are likely to become reality, and people will be able to play a variety of exploratory movie games on the streets with the help of virtual devices such as VR. These scenes and visual images that come from the film and reflect into the real world will feed back into the film itself and become an important part of the film. The $5 \mathrm{G}$ era is an era that fully integrates augmented reality (AR), VR, AI, and smart wearable (IW) technologies. The breaking of technological barriers will completely reshape the spectacle of film art, the concept of time and space, and the way of watching, and create a realistic virtual environment in the multi-dimensional information space, which can make film users feel immersive and show the interaction and ability of perfect integration with the environment. VR films in the 5G era will definitely amass a large number of followers. VR films will become another epoch-making mass consumption product after 3D films, and audiences in 5G films will be given the choice of double scenes of self-viewing and gathering plots. At the same time, with the application and innovation of various advanced technologies in the field of movies in the 5G era, postmodern culture is also rising again in movies.

\section{Factors of the rise of postmodern film culture in $5 \mathrm{G}$ era}

\subsection{Application scenario expansion}

First, "ultra HD video (4K/8K) will be the first entry point for the future. According to industry estimates, China's ultra HD video industry will reach a scale of more than 4 trillion yuan by 2022, gaining a leading position in the world." [3] Based on the features of 5G with high bandwidth, low latency and large connection, scenes combining 4K/8K ultra HD video and 5G technology are emerging, further improving the smoothness, delicacy and fidelity of images. Audiences can see clearer picture details on movie screens and ultra HD video content. Even the hair, pores and facial expressions of the characters in the movie can be seen in a glance, greatly improving users' visual experience.

Second, with the development of 5G network technology and the improvement of film business, the combination of traditional cinema transmission mode and new technology and new media mode in the 5G era will greatly increase the development quality and market space of traditional film in the post-epidemic era. China Mobile MIGU has introduced innovative "new games" such as cloud cinema tickets, cloud box and cloud interview, through which "cloud audience" can enter the "cinema on cloud" that will never end [4].

According to statistics, "in recent years, the number of 3D films released and the box office ratio in the North American film market have gradually declined, and the 3D market has stagnated and this trend will persist. The main reason for this phenomenon is that the $3 \mathrm{D}$ technology is insufficient to meet the needs 
of the audience ${ }^{[5]}$." VR/AR film is regarded as one of the "killer" application scenarios of the film industry in the $5 \mathrm{G}$ era. As a large number of data and computation-intensive tasks are transferred to the Cloud, VR/AR devices can completely bid farewell to the transmission mode of wire connection. In the future, "Cloud VR+" will become a typical example of the integration innovation of "VR+" and 5G. It can solve the pain points such as insufficient rendering ability and 3D imaging ability, weak interactive experience and poor terminal mobility in VR/AR film production, promote the production and innovation of highquality content resources of VR films, and deliver the most immersive experience to the audience.

Finally, in the $5 \mathrm{G}$ era of Internet of Things (IoT), every connected product can become an intelligent media. "The window mode and window period rules are changing" for movie viewing in the $5 \mathrm{G}$ era, and "parallel Windows will emerge as a non-mainstream movie distribution mode." ${ }^{[6]}$ Cinema or movie with $5 \mathrm{G}$ of large bandwidth, rapid connection and low delay can provide multi-screen display and cross-screen display, and will also leave room for the survival and development of diversified forms of movies. Harmony OS 2.0 was officially released on June 2, 2020. As 5G era is oriented at full scene operating system, it can be implemented in mobile phones, PC, tablet, wisdom, screen, watches, bracelets, etc.; for instance, intelligent motor-screen displays the interconnectivity, multiple screen synergy, and depth fusion, and is free to switch. Thus form of flexible adaptation in the whole scene and rich terminal form greatly expands the future of film industry and ecological construction. The multi-screen viewing and interactive experience of movies in the $5 \mathrm{G}$ era has been improved.

\subsection{Whole industry chain innovation}

Under the background of $5 \mathrm{G}$, every link of the whole film industry chain may usher in innovation, from the content production of the most important basic part of the front end, to the publicity, distribution and screening of the communication process, and then to the creation and production of various IP opening and derivatives at the back end.

First, content production. Internet enterprises are becoming increasingly dominant and influential in the market and industrial chain, the absolute core role of directors and screenwriters may be diminished, film users will become the main body of creative production, and online film will gradually become a new way of film production and become independent. Secondly, propaganda and marketing. In the 5G era, traditional copy transmission, hard disk express and mails will be eliminated, and a more secure, economic and efficient distribution transmission system will transform the distribution mode. Video marketing and cloud delivery will become the mainstream of film promotion. "In the future, there will be more film and television that reflect our life, and film and television content will be released in an all-round, multi-angle and low-cost way." " ${ }^{7]}$ Third, investment financing. In the context of 5G, investment and financing based on big data and intelligent algorithms will play a role in the front-end of the value chain of the film industry. For the large digital investment and financing organizations in the consumer market, all kinds of algorithm are recommended. The efficiency of asset location tracking coverage will be significantly increased to effectively control the cost and power consumption so that the film industry can thrive in a healthy and development space and avoid the waste of resources and market turmoil. Finally, derivative development. In the context of 5G, there will be more IP development and derivative production at the back end of the film industry chain.

\subsection{Evolution of film aesthetics}

Film aesthetics under the background of $5 \mathrm{G}$ will usher in new changes, especially VR/AR films under 5G technology, which will subvert the traditional film aesthetic concept and reshape the new film audio-visual language.

First, the hyperspace-time structure. The basic physical property of a traditional film is that it is 
displayed on a certain screen size, and the media space it depends on is the two-dimensional plane on the screen in front of the audience. Irrespective of 3D movies, 4D movies and 5D movies, the use of 3D glasses, smart seats or other sound and light can help improve the object projection that enhances the scene of authenticity, but the audience's attention is always fixated on the two-dimensional screen. With the application of 5G technology, VR movies will overcome the limitations of 2D screen. Scenography of its linear zoom will replace the traditional films, and the audience's point of view can moving in threedimensional space, free to choose stories and to switch the focus and scene. The story will not be suspended because of someone leaving. The entire imaginary world is still in operation even when the story ends.

Second, the long-shot narrative. Different from the long-shot narration in traditional movies, the special feature of VR movies with 5G technology lies in that the concept of time in traditional movies has been completely replaced, and the time in the virtual world and the real world in movies are consistent and synchronized. Filmmakers can no longer use montage to connect different images to form rich and profound symbolic meanings according to the intention of the play, nor can the time relationship be disrupted, using flashback, skip and other techniques to reset or compress space and time. In the virtual and single long-shot world of VR movies, time is controllable, and the audience can decide to pause, rewind, fast-forward the entire virtual world, or freely weigh the events occurring in different spaces at the same time. Single longshot narration is the main narrative strategy, if not the only one, for VR films under 5G background.

Third, the interactive experience. Traditional film art is a kind of static visual presentation art similar to painting, photography and other image art. The user keeps a certain distance from the aesthetic object of the film, and does not directly intervene in the expression of the aesthetic object of the film, but obtains aesthetic experience through static observation. For 5D movies and VR/AR movies under the background of $5 \mathrm{G}$ technology, our bodies will also be fully involved in movie watching and gamification "playing" through various forms such as intelligent head display and intelligent seat. In this mode of experience, users will become participants and creators of movies, instead of passive recipients. They can interact with each other like playing a video game. They can influence the development of the plot and decide the fate of key characters by participating in the plot selection. After interacting with the film, everyone can have a film of his own style, so as to truly obtain the interactive aesthetic experience.

\section{Postmodern cultural enlightenment of movies in 5G Era}

In addition to the main reasons of scene, aesthetics and industrial chain transformation, technological desire, data hegemony and trade protectionism rise in the double dimension of 5G and "post-epidemic" clarify postmodernism in the film industry. In such a context of "likeness," which is replicated and simulated in large quantities, we will gain more enlightenment by sticking to the right path of the development of film art and film industry and staying true to our original aspiration.

\subsection{Being a provider of high-quality content ideas}

With the integration of $5 \mathrm{G}$ and film development, the production and creation, shooting and production methods of film content creativity will split, and digital cloud production and cloud production platform will gradually replace the traditional film production and shooting mode. Traditional film/video resources are constantly deconstructed and hidden, and massive film production will lead to a further surplus crisis of film works. A large number of vulgar, mediocre and superficial films may appear at every corner of the Internet and cultural industry. The film industry should adhere to the principle of "content is king" and produce more high-quality content and excellent works. This is the only way to attract users, create greater and stronger adhesion between film products and users/audiences, and maintain the lasting vitality of film art. 


\subsection{Being a trainer of high-end film talents}

Postmodernism emphasizes human subjectivity, which is beneficial to the cultivation of innovative talents to some extent. In the $5 \mathrm{G}$ era, we should strengthen the cultivation of compound and application-oriented talents for film. Especially, we should strive to cultivate a large number of high-end technical engineering talents urgently needed in the China's film industry, so that more VR film production talents and VR film directors have the opportunity to lead China's film industry. Colleges and universities should be taken as a platform to attach importance to the cultivation of film creative talents. From the perspective of discipline construction, we should construct a talent education system adapted to the new development pattern as this is an important part of the development of film and television industry ${ }^{[8]}$. This comprehensive talent training system should comprise of undergraduate, master to doctorate students.

\subsection{Being a disseminator of advanced cultural concepts}

In the 5G era, the diversified application of various high-tech scenes and the mobile, intelligent and interactive information reception complicates the production and dissemination of movies, thereby laying a foundation for all kinds of vulgar and inferior movies. Postmodernism also has negative factors in the construction of China's film culture industry. We should resolutely resist and criticize the wrong attitude and way of life advocated by it. For example, although VR feature films are still immature and have not won a place in cinema films, VR short films are rising in the live video market. In particular, a large part of these VR live videos are suspected of vulgar and pornographic scenes and content; therefore, this requires our special vigilance. "From the perspective of production, the key to effectively realize cultural value lies in improving the quality of film creation and enriching the cultural connotation of films as much as possible." [9] Therefore, we should stick to our confidence in film culture and spread China's advanced culture by telling good Chinese stories.

\subsection{Being the guardian of data and information security}

Compared with $4 \mathrm{G}$, the film industry in the $5 \mathrm{G}$ era will no longer need the help of large data centers, but rely on blockchain technology to provide point-to-point data transmission, which can effectively ensure the reliable stability of the system and provide better film services. This kind of blockchain technology makes "the tradition unified and orderly technical structure dissolved, technically realizing the deconstruction goal of postmodernism" and "realizes the postmodernism cancelling system center idea." [10] This matches French postmodernist Gil Deleuze's criticism on decentralization and totality. However, 5G technology cannot serve the network and data information security once and for all. In the context of 5G, the security of information and data will become a key topic of concern. We should be committed to solving and ensuring the security of users both now and in the future.

\section{Summary}

With the integration of 5G technology, film art and film industry, postmodernism has once again manifested itself in film culture. Exploring the origin and main reasons of postmodern film culture in the 5G era will help us deeply understand the important role and influence of 5G technology in enabling film art and film industry. At the same time, we must have a clear understanding of the impact of $5 \mathrm{G}$ and other advanced technologies on film art and the film industry. We must stick to the right path of film development and promote the sustained and stable development of film art and the film industry.

\section{Funding}

This paper is the periodical achievement of "Research on Innovation and Development of Guangzhou Film Industry under 5G Background" (Number: 2021GZGJ296). This paper is the phased achievement of 
"Research on the Development Strategy of Film and Television Industry under 5G Vision" (Number: 2020HSDS13), which is the tutor system scientific research project of Guangzhou Huashang College in 2020. This paper is the phased achievement of "Film and Television Special Effects" (Number: HS2020ZLGC22) of the "University-level Quality Project" construction project of Guangzhou Huashang College in 2020. This study is also supported by Guangzhou Huashang College.

\section{Disclosure statement}

The author declares no conflict of interest.

\section{References}

[1] Yang M, 2008, The Pursuit of Social Commonality in the Open Era of Diversified Values -Sociological Thinking on the Change of Public values in the Past 30 years of Institutional Reform. Gansu Social Sciences 000.005(2008):2-7.

[2] Lan F, 2017, Re-reading of Post-modern Film Theory. Journal of Southeast University (Philosophy and Social Sciences), 2017(02): 130-148.

[3] Liu H, 2020, Opportunities, Challenges and Countermeasures of Film Industry Development Under the Background of 5G Technology. Film Arts, 2020(05): 155-160.

[4] Financial and Economic Observation. 5G Enabling film, China Mobile MIGU Explores the Path of Film Reform in 5G Era. Sohu. https://www.sohu.com/a/425143995_589567 (Accessed October 16, 2020).

[5] Li Y, Are 3D Films Becoming less Popular? Understand the Current Situation of the Development of Global Film Market. Released December 28, 2018. https://t.qianzhan.com/caijing/detail/181227$722694 \mathrm{ca} . \mathrm{html}$

[6] Yin H, Xu X, 2020, Reconstruction of the "Window Mode" of Film Distribution and the "Priority Status" of Cinemas. Contemporary Film, 2020(09): 4-12.

[7] Han X, Liu R, 2020, Research on the Development and Reform of Film and Television Industry Under 5G Background. Journal of China Radio and Television, 2020(1): 29-32.

[8] Zhao Y, Fan J, 2021, New Infrastructure, New Formats and New Development of Chinese Film industry -- A Summary of the Symposium on Film and Television Industry Development in the PostEpidemic Era. Contemporary Film, 2021(01): 173-176.

[9] Jia L, 2007, The Spiritual Map of Chinese Films -- On the transmission path of mainstream films and cultural core values. Contemporary Film (03), 24-28.

[10] Huang X, 2018, Big Data Revolution and Postmodernism. Journal of Shandong University of Science and Technology (Social Science Edition), 2018(02): 1-8. 